\title{
The Intersection of Personal and Professional Stress in The Lives of Public Middle School Teachers: A Qualitative Case Study
}

\author{
Bridgette Wicke and Timothy R. Nelson ${ }^{1}$ \\ Liberty University, United States
}

\begin{abstract}
The purpose of this case study was to examine the intersection of personal and professional stress in the lives of public middle school teachers. Many aspects of a teacher's professional life contribute to stress and burnout, including pressures from administration, time pressures, observations, assessments, workload, classroom management, discipline, student learning, and motivational issues. Many aspects of a teacher's personal life contribute to stress and burnout, including family responsibilities, finances, and time pressures. In order to overcome pressures at work and home, teachers need to develop successful strategies or coping mechanisms. Other times, teachers burn out and quit the profession. The central research question for this study was, how do public middle school teachers describe the stress that impacts them in their professional and personal lives? The theory guiding this study was burnout theory by Maslach and Leiter. Ten public middle school teachers in central Florida were examined in a case study. To gather data needed for this study, interviews were conducted, a focus group interview was used, and letters written by teachers were examined. Data analysis utilized open coding and the identification of themes or classifications. Understanding patterns and themes of teacher stress, burnout, and coping strategies can help to reduce teacher burnout and attrition.
\end{abstract}

KEYWORDS: Coping Strategies, Middle Schools, Stress, Teacher Burnout, Teacher Shortage.

The teacher shortage in the United States is one of the worst problems facing schools today (Newberry \& Allsop, 2017; Oyen \& Schweinle, 2021). The teaching profession has steadily become less stable as teacher attrition rates have increased to the point that more teachers leave voluntarily rather than remain in the classroom until retirement (Day \& $\mathrm{Gu}, 2010$; Glazer, 2018; Ingersoll et al., 2014). Teacher well-being is influenced by many factors, including school climate factors, administration factors, and student factors (Harmsen et. al., 2018; Hong 2012; Yu et. al., 2016). Teaching, both strenuous and dynamic with its everchanging rules, regulations, curriculum changes, and atmosphere, has led to a high rate of burnout as compared to other professionals such as environmentalists, physicians, and engineers (Aguilar, 2018; Bernard, 2016; Rupesh \& Bibhas, 2017). Conceptually, burnout is professionally related, with later stages of burnout being individually invasive and pervasively affecting non-work areas of life as well (Maslach \& Leiter, 1997; Szigeti et al., 2016). Many teachers experience an intersection of stress from both their professional and personal lives.

Teachers' personal perceptions of their work as well as their stress burden play a role in their teaching effectiveness with recent finding suggesting that teacher burnout can negatively affect students' emotional well-being (Oberle et al., 2021). Identifying the sources of educator stressors is the first step in determining an appropriate plan to developing coping or resolution

\footnotetext{
${ }^{1}$ Corresponding Author: Instructor at Liberty University in Virginia, United States. E-mail: trnelson2@liberty.edu
} 
strategies. Although varying widely, there are a multitude of options available to alleviate the symptoms of burnout before it escalates (Mulyani et al., 2021). Maslach and Leiter (1997) define burnout as the prolonged response to chronic emotional and interpersonal stressors on the job, and it is comprised of three dimensions including exhaustion, cynicism, and inefficacy. Burnout theory, as it relates so closely to depression and stress, is of great importance because it has been associated with diminished job performance, health problems, withdrawal behaviors, absenteeism, and depression (Glazer, 2018; Zysberg et al., 2017). Improvements need to be made on structural levels alongside with implementations of teacher training with special focus on stress, coping methods, and self-awareness to ensure all children's fundamental rights towards a healthy education (Huberman et al., 1993; Szigeti et al., 2016).

The purpose of this case study is to examine the intersection of personal and professional stress in the lives of public middle school teachers. Although teacher stress and burnout have been studied, there is a lack of empirical literature on middle school teachers or the intersection of personal and professional stress in middle school teachers. For this study, stress will be defined as a disparity between a person's perceptions of environmental demands and their perceived ability to cope with those demands (Pignata \& Winefield, 2013). Maslach and Leiter (1997) define burnout as the prolonged response to chronic emotional and interpersonal stressors on the job. Four aspects of a teacher's role may contribute to stress, classroom discipline and management, student learning and associated emotional and motivational issues, workload and time pressures, and experiencing problems with school administration (Bernard, 2016). The strenuous and dynamic occupation of teaching has led to a high rate of burnout as compared to other professionals (Rupesh \& Bibhas, 2017). Burnout theory is important, because as it relates to stress, burnout has been associated with diminished job performance, health problems, withdrawal behaviors, absenteeism, and depression (Zysberg et al., 2017).

\section{Literature Review: Theoretical Context}

Maslach and Leiter (1997) defined burnout as the prolonged response to chronic emotional and interpersonal stressors on the job. Burnout, according to Maslach (2003), is comprised of exhaustion, cynicism, and inefficacy. This is a multidimensional model to stress that goes beyond the individual stress experience (exhaustion) to encompass (cynicism) and feelings of inefficacy (Maslach, 2003). The first dimension, the exhaustion dimension, is also described as wearing out, loss of energy, depletion, debilitation, and fatigue (Maslach \& Leiter, 2016). The second dimension, the cynicism dimension, is also called depersonalization, and is described as negative or inappropriate attitudes, irritability, loss of idealism, and withdrawal (Maslach \& Leiter, 2000). The third dimension, the inefficacy dimension, was originally called reduced personal accomplishments, and is described as reduced productivity or capability, low morale, and an ability to cope (Maslach \& Leiter, 2000).

Burnout is divided into six categories in order to properly assess individuals and organizations at risk of burnout. These six categories provide individuals and organizations with the framework, along with the necessary tools, to move from burnout towards engagement. These six categories of burnout include (a) workload, (b) control, (c) reward, (d) community, (e) fairness, and (f) values (Maslach \& Leiter, 1997). This six-area burnout framework has now been incorporated into assessment programs for organizations and individuals (Maslach \& Leiter, 2000). The framework can be used to diagnose which categories are especially troublesome for them, and then design interventions that target the diagnosed problem areas (Maslach \& Leiter, 2005). To alleviate burnout, organizations and individuals must identify the areas in which their mismatches lie and then design solutions tailored to improve the fit within each area (Maslach \& Leiter, 2000; Maslach \& Leiter, 2005). Symptoms of burnout and symptoms of depression are similar and teacher burnout can lead to increases in depressive symptoms (Shin et al., 2014; Szigeti et al., 2016). In burnout research, a strong relationship 
between exhaustion and cynicism is found consistently across a wide range of settings (Maslach, 2003).

\section{The Impact of Stress on Burnout and Teacher Attrition}

Attrition rates of teachers have increased to the point that more teachers leave voluntarily rather than remain in the classroom until retirement (Carver-Thomas, 2017; Farmer, 2020; Sorenson \& Ladd, 2020; Xin, et al., 2021). Bernard (2016) found that highly stressed teachers have unhelpful ways of thinking about themselves, and stress-prone teachers hold beliefs about the high work demands they experience (hours of teaching, preparation, corrections, meetings, and general paperwork), which are concomitant with high stress and which may significantly exacerbate stress. When there are chronic interpersonal stressors on the job, burnout is a psychological syndrome that emerges as a result (Maslach \& Leiter, 2016). Teachers on the verge of burnout might not greet their colleagues, avoid sharing their classroom experiences, have poor classroom management skills, and neglect to socialize with colleagues (Aguilar, 2018; Iancu et al., 2017). One primary source of teacher stress is the experience of negative emotions in the classroom and the challenge of managing these emotional experiences (Iancu et al., 2017; Katz et al., 2017).

Teacher shortages and teacher attrition are the two main concerns in staffing America's schools (Newberry \& Allsop, 2017). It is not only the beginning teachers that are leaving the teaching profession at alarming rates; it's the experienced teachers as well (Glazer, 2018). During the first two years of teaching, which is referred to as the 'survival period,' teacher attrition rates are at its highest (Day \& Gu, 2010), and although teacher attrition does slow down after the first two years, it does not stop there (Glazer, 2018). It was concluded that stress causes and lack of resources result in emotional exhaustion, which significantly relate to intention to leave the profession (McCarthy et al., 2015). What makes teacher attrition even worse is that teacher turnover is higher in high-poverty schools and seems to be the highest in urban middle schools (Cross \& Thomas, 2017). There is a strong relationship between mental health and teacher attrition, so supporting teachers' mental health could be an important part of breaking this cycle, especially if this support comes early on when teaches are particularly vulnerable to negative experiences (McLean et al., 2017; Woloshyn \& Savage, 2018).

A teacher's perceived physical health and perceived mental health can impact stress and attrition (Bogaert et al., 2014). Teachers are found to have poorer perceived mental and physical health than a general healthy population (Bogaert et al., 2014; Uzman \& Telef, 2015). Recharging comes from doing things like taking lunch away from your desk, reading a book for fun, spending time with colleagues, or talking about a favorite TV show (Aguilar, 2018). While analyzing teachers' mental health, two out of five teaches had high intensity of distress and $42.5 \%$ of teachers were at danger of burnout (Uzman \& Telef, 2015). Teachers' emotion regulation strategies may affect their ability to cope with the stressors they experience in their work, so it is important to study the relationship between specific emotion regulation strategies and stress regulation (Katz et al, 2017). When it comes to job performance, less reactive people cope better with uncertainty in their jobs than do highly reactive people. Less reactive individuals generally use more effective coping strategies, whereas highly reactive individuals do not (Harmsen et al., 2018).

Resilient people draw boundaries, recognize their limits, and know when to step back to avoid overcommitting themselves (Aguilar, 2018; Mulyani et al., 2021). Understanding teachers' mental health is important not only for the objective of supporting teachers, but also because these symptoms have implications for students (McLean et al, 2017). Results of studies support the efforts of emerging teacher interventions targeting emotion regulation strategies to improve teachers' ability to manage occupational stressors and promote their well-being (Harris et al, 2015; Katz et al, 2017). The benefits of minimizing professional stressors may include 
improved job satisfaction and higher teacher retention rates, as recent researchers have emphasized the role of school conditions and characteristics in teacher turnover (Mclean et al., 2017; Stauffer \& Mason, 2013). A teachers' interaction with her students affect how they perform and how well they will score on tests (Durour \& Marzano, 2013).

\section{Stress and Leadership}

Only a capable leadership which is able to involve teachers in decision-making, is willing to listen and accept contributions from everyone, uses comprehensive communication, enhances differences, recognizes results, and which offers opportunities for professional training, can produce quality and well-being of teachers (Ford et al., 2019; Simone et al., 2016). Effective leadership should apply the principles of empowerment to create a positive workplace environment where the feelings of others are taken into consideration. Empowering leadership encourages independent action, teamwork, and self-development (Tuckey et al., 2012). There is a statistically significant, positive correlation, between the teacher-perceived transformational leadership style and subscales of middle school principals to teacher efficacy (Fullan, 2010; Fuming \& Jiliang, 2007). Research suggests teacher efficacy is critical to student achievement and therefore it is important to investigate the relationship that school leadership has to teacher efficacy (Gentilucci \& Muto, 2007). In order to decrease workload and improve teachers' perceptions of senior management, leadership should become trained adequately in managing their staff based on the involvement of teachers in decision-making (Simone et al., 2016). Stress caused by teachers' workload can be reduced through actions aimed at supporting a leadership style that will increase autonomy and individual empowerment. (Yu et al., 2016). Scholars note that individual empowerment can oftentimes be achieved through actions aimed at improving communication through participation and sharing (Simone et al., 2016).

School district administrators who hope to keep competent teachers should proactively search for the means to minimize and alleviate stressors and to encourage faculty to participate in those activities (Cancio et al., 2018). If teachers are forced to compete, and not work together, it is entirely likely that lesson plans and best practices may not be shared in a spirit of collaboration (Brewers et al., 2015). Effective administrators must cultivate and communicate an acceptance of emotions and offer professional development tied to emotional resilience, incorporating emotional literacy, learning to understand, name, and engage with emotions in healthy ways (Tuckey et al., 2012). Administrators must also show the value of self-care by modeling and taking care of themselves (leaving school at reasonable hours, for instance), and they must give others permission to do so (Aguilar, 2018). Teacher educators have a responsibility to provide information on teacher stress and coping strategies in teacher preparation courses to give teachers the skills to deal with stress and burnout in an effective manner (Cancio et al., 2018).

\section{Stress and Life Events}

In 1967 psychiatrists Thomas Holmes and Richard Rahe created a list of 43 life events based on a relative score (Holmes \& Rahe, 1967). The 43-item Holmes and Rahe Social Readjustment Rating Scale, now commonly known as Social Readjustment Rating Scale (SRRS), is used as a measure of stressful life events. Life events include things such as marriage, pregnancy, divorce, jail time, and change in living conditions. Each event, called a Life Change Unit (LCU), has a different 'weight' assigned to it that determines the stress factor (Holmes \& Rahe, 1967). The higher the score, and the larger the weight of each event, the more likely the patient would become ill from stress related life events. The SRRS is one of the most widely cited measurement instruments in stress literature, but it is old (Scully \& Tosi, 2000). Chronic and acute stress, and the demanding features of daily life, can serve as a blockade to 
good health practices and lead to an unhealthy lifestyle (Burg et al., 2017). There is a significant negative effect of exercise on stress but there is also found to be significant between-person variability. The relationship of stress to exercise can be bi-directional and varies from person to person (Burg et al., 2017). For some, regular physical activity can alleviate the physiological impact of chronic and acute stress while improving aspects of stress resilience (Cancio et al., 2018). For others, physical activity has no impact on stress, or the anticipation of exercising causes a heightened sense of stress. Psychosocial stress contributes to poor health in part by adversely affecting maintenance of healthy behaviors (Burg et al., 2017).

\section{Stress and Coping Strategies}

Research in coping strategies is necessary to inform interventions that support growth in teacher resilience, as well as continued positive school climate development through evidence-based approaches (Gray et al., 2017). In the analysis of coping strategies for teachers, it was found that listening to music, feeling supported by family and friends, and dancing were strategies that predicted lower stress (Cancio et al., 2018). Other coping strategies included counseling, eating, using prescription medication, using of alcohol, and use of recreational drugs, all of which increased teachers' stress (Cancio et al., 2018). During active coping strategies, teachers attempted to change the source of stress, or themselves, by engaging in leisurely activities such as dancing, yoga, exercise, and emotional support from family and friends (Burg, et al., 2017). In contrast, in maladaptive coping strategies, teachers avoid or deny the source of stress (Cancio et al., 2018). Maladaptive coping strategies, like alcohol, drugs, and prescription medicine, were found to be predictors of stress (Mclean et al., 2017).

Some teachers use prayer or religion as a strategy or coping mechanism to combat stress and reduce burnout (Hartwick, 2013). Studies have shown that school-based implementation of mental health training and support for teachers can lead to positive outcomes for both teachers and their students through improvements in classroom climate, teacher sensitivity to student needs and behavior management, as well as diminished teacher burnout, anxiety, and depression (Mclean et al., 2017). A healthy work environment can be reached not only through the absence of negative factors, but also by promoting positive characteristics (Simone et al., 2016). While stress can be very personal and vary from person to person, teachers need to make self-care a priority, and teachers need to feel safe in talking about stress without fear of stigma (Ferguson et al., 2017). The stigma of teacher stress appears to be a prevailing problem within the teaching profession but addressing stress during pre-service education could help alleviate some of the stigma of discussing stress in their future careers (Ferguson et al., 2017). Learning to relax, mindfulness, exercise, sleep, resolving conflict, and positive psychology were all found as effective ways to reduce stress with teachers (Taylor, 2018). School-based implementation of metal health training and support for teachers can lead to positive outcomes for both teachers and their students through improvements in the classroom climate as well as diminished teacher burnout, anxiety, and depression (Roser, 2013). Pre-service teachers could benefit from mental health training and support before they start their careers (McLean et al., 2017). Even a short, multi-modal approach to enhance well-being could be used to make significant changes to teachers' lives in the school setting (Taylor, 2018). It is critical for teachers to deal with the work stressors of their profession using coping strategies, work-life balance, meaningful collaboration, support from coworkers, and support from teaching staff (Harmsen et al., 2018). Despite the importance of teachers' emotional experiences, most teachers have never experienced any professional development sessions that talk about how to handle emotions in the classroom or how to recover from emotional trauma (Hong, 2012; Woloshyn \& Savage, 2018). 


\section{Situation to Self}

Bridgette Wicke - During my fifteen years of teaching, I have witnessed the consistent lack of quality educators due to burnout. As a current middle school teacher, I continue to experience teacher shortages getting worse. I have changed schools, and contemplated switching careers, due to my own personal burnout. Over the years, I have witnessed new teachers, along with veteran teachers, leaving the teaching profession at an alarming rate. I am interested in this topic as an attempt to retain high quality educators in the classrooms.

Timothy R. Nelson - As a current middle school teacher and former administrator, I experienced burnout early in my career. I changed schools three times in my first five years of teaching. I am interested in this topic due to experiencing working in an excellent middle school with an incredible administrative team and expert colleagues. Our middle school is not without fault - we are challenged with difficult situations on a daily basis. Despite the challenges, the faculty lives out many of the research findings as we strive to build a school based on respect, organization, achievement, and responsibility.

\section{Case and Methodology}

The present study is a qualitative single case study and includes collecting quotes from people, verifying them, and contemplating what they mean (Patton, 2015). One rationale for selecting a single-case study, rather than a multiple case study design, was that the single-case can represent the critical test of a significant theory (Yin, 2018). Another rationale for selecting a single-case study design was the present study was looking at a common case. The common case studied here was the stress that impacts public middle school teachers in their professional and personal lives. The setting for this study is a large public middle school of approximately 1,100 students in the Southeastern United States. Approximately $40 \%$ of students are reported as White and 59\% of students are reported as minorities. Sixty-four percent of students at this school qualify as economically disadvantaged. This setting was chosen because there is a gap in the literature pertaining to causes of teacher stress in public middle schools.

Table 1

Demographic Information and Reported Stress Levels

\begin{tabular}{llcccc}
\hline Name & Gender & $\begin{array}{c}\text { Years of } \\
\text { experience }\end{array}$ & $\begin{array}{c}\text { Age of } \\
\text { participant }\end{array}$ & Stress level at work & $\begin{array}{c}\text { Stress level at } \\
\text { home }\end{array}$ \\
\hline Anne & Female & $0-5$ & $18-28$ & 10 & 1 \\
Eric & Male & $6-10$ & $29-39$ & $3-10$ & $5-6$ \\
Gabby & Female & $11-15$ & $40-50$ & $3-8$ & $1-10$ \\
Gavin & Male & $11-15$ & $29-39$ & $7-8$ & 5 \\
Heather & Female & $0-5$ & $18-28$ & 7.5 & $6-7$ \\
Julia & Female & $11-15$ & $40-50$ & 10 & $7-8$ \\
Kinsley & Female & $16-20$ & $40-50$ & $5-10$ & 3 \\
Marissa & Female & $6-10$ & $29-39$ & $3-10$ & 8 \\
Pam & Female & $6-10$ & $29-39$ & 9 & 5 \\
Val & Female & $16-20$ & $29-39$ & 8 & 3 \\
\hline
\end{tabular}

*on a scale of 1 to 10 , with 1 being very low stress and 10 being very high stress

Permission to conduct the study was obtained from the local school district and the Institutional Review Board. In addition to a consent from, questionnaires were sent via email to obtain demographic information (experience, gender, race). From a pool of 54 teachers (36 female/18 male), ten public middle school teachers consented to participate. Purposeful 
sampling was used to best inform the research questions and enhance understanding of the phenomenon under study (Patton, 2015). Twelve participants agreed to complete the study, but two had to withdraw due to personal responsibilities. All participants were currently dealing with stress and/or burnout, willing to participate, unknown to either researcher, and maximum variability in race and gender were attempted. See Table 1 for information on participants (pseudonyms).

\section{Data Collection}

To achieve triangulation (Creswell, 2007; Patton, 2015), the data collected for the case study included a screening questionnaire, individual interviews, a single focus group interview, and document analysis of letter-writing samples. The screening questionnaire served only to select the most appropriate participants for the study. Every participant received a screening questionnaire to find out more about their levels of stress. Questionnaires were 7 questions long and were adapted from the Readjustment Rating Scale (Holmes \& Rahe, 1967; Scully \& Tosi, 2000). Evidence from these multiple sources increased the confidence that my case study was accurate and strong (Patton, 2015; Yin, 2018). One of the most important sources of case study evidence is the interview (Yin, 2018). Participants were asked to introduce themselves and discuss stress in their personal and professional lives. Some of the questions were "As you think about your workday, what are some events or situations that cause you a lot of stress?" "What are some things you do, some coping mechanisms, or some strategies you have in place at work, to lower your stress levels?" and "As you think about your home life, what are some events or situations that cause you the most amount of stress?" Follow up questions were asked during the semi-structured interview (Yin, 2018).

The focus group for my study was conducted online using video chat software. The focus group procedure calls for me to recruit and convene a small group of participants, then moderate a discussion about some aspect of the case study, deliberately trying to surface the views of each person in the group (Yin, 2018). One focus group was conducted with $\mathrm{X}$ participants and it lasted approximately 45 minutes. Focus group interviews have several advantages for qualitative inquiry, including cost effective data collection, highlighting diverse perspectives, and interactions among participants enhance data quality, topics avoided or silences are revealing, and analysis unfolds as the interview unfolds (Patton, 2015). Participants were asked to describe their stress levels during the work day, at home, and how stress at home impacted their work at school. The use of open-ended responses are the heart of qualitative data, and they emerge from asking open-ended questions (Patton, 2015).

Each participant wrote a letter to a first-year teacher. In the letter, they were able to personalize their experiences and descriptions of teaching. These letters, one from each participant, served as case study evidence called "physical artifacts" (Yin, 2018, p. 125). By examining the letters to a first-year teacher, the case study researcher is able to develop a broader perspective concerning all of the classroom stressors and applications over a much longer period of time, far beyond that which could be directly observed in the limited time of a classroom visit (Yin, 2018).

\section{Data Analysis}

The first technique during data analysis was open coding. The interview transcripts were read, reread, and analyzed with inductive coding methods (Creswell, 2013). A short list, with five or six categories, along with shorthand labels or codes were established. A computer coding software program, NVivo, was used for data analysis. The interviews and focus group discussions were transcribed into Microsoft Word; and, along with letter writing samples, all documents were uploaded into NVivo coding software program. Memos were created in the 
NVivo program to connect the nodes and discover relationships or patterns. I worked with the data collected and searched for insights, concepts, or themes that seemed promising. Using the NVivo word frequency query, the top 100 words from all the data collected through the study, was gathered and displayed in a word cloud. The figure below displays the results of the top 100-word cloud.

Figure 1.

Word frequency query word cloud using the NVivo coding program.

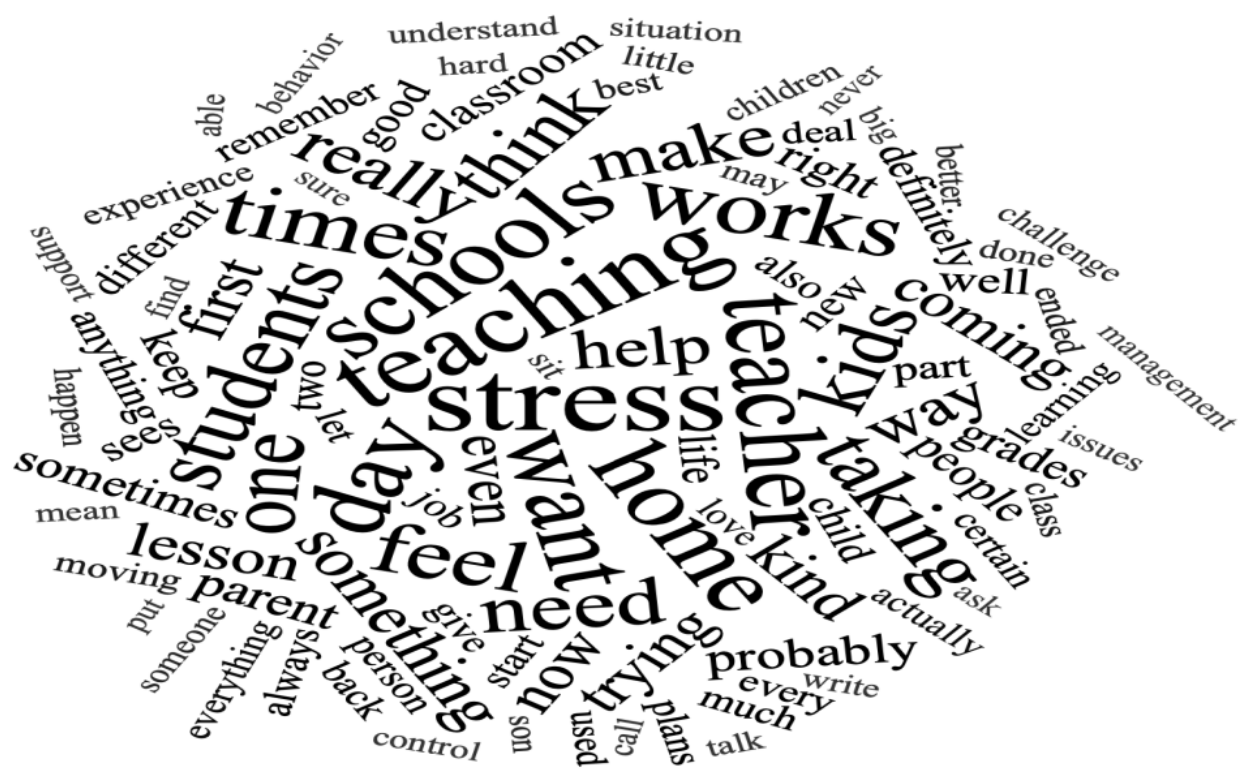

The four major themes that surfaced were intersecting relationship stress, intersecting environmental stress, coping with relationships, and coping with the environment.

\section{Theme 1: Intersecting Relationship Stress}

Through the data analysis process, the first theme that emerged was intersecting relationship stress. Stress with coworkers, stress with students, and stress with family members or loved ones were the reoccurring subthemes found in the data within intersecting relationship stress (see Table 2).

\section{Table 1}

Theme 1: Intersecting Relationship Stress

\begin{tabular}{ll}
\hline Subtheme & Code (frequency) \\
\hline Coworkers & Lack of communication (12) \\
& Lack of understanding (8) \\
& Lack of follow through (6) \\
& Classroom behavior (11) \\
Students & Hallway behavior (10) \\
& Lack of motivation (7) \\
& No time and/or no energy (9) \\
& Health concerns (8) \\
Loved Ones & Finances (5) \\
\hline
\end{tabular}

*The number in parenthesis represents the number of times each code was found in the data. 


\section{Coworkers}

Stress with coworkers was the first reoccurring subtheme found within intersecting relationship stress. Many aspects of a teacher's role may contribute to stress, which include, classroom discipline and management, student learning associated with emotional and motivational issues, workload and time pressures, and experiencing problems with school administration (Bernard, 2016). Criticism, critique and comparison can serve as additional sources of stress, including the constant comparison within schools trying to reach and maintain the required level of state testing and scores that match (Brewer et al., 2015). This constant comparison can often pit teachers against one another. In the focus group interview, Julia mentioned relationship stressors, and many other teachers agreed and related to the statement:

As teachers we're trained to deal with everything we deal with in the classroom, with the actual teaching itself, but they don't provide any instructions on interpersonal relationships with peers or dealing with the outside stresses that come along with teaching.

When asked in the interview what caused her the most stress at work, Marissa stated

A lack of clarity and unity, and enforcing rules throughout the school, where there is sometimes not a united front among the teachers, and it causes some divisiveness. I would say some of my fellow colleagues are nay-sayers and ... they are kind of against any new change that might help benefit some, you know.

\section{Students}

In addition to stress from coworkers, teachers agreed that students were a source of stress. Understanding teachers' stress levels and mental health is important not only for the objective of supporting teachers, but also because these symptoms have implications for students (McLean et al, 2017). A positive school climate where students are showing academic achievement, there is an atmosphere of caring, students and teachers feel safe, and there is a feeling of connectedness between students and teachers are all critical for teacher well-being (Harmsen et al., 2018). A teacher's well-being will have a big impact on a student's well-being (Hong, 2012). During the interview, Gabby discussed how students can be the most stressful part of the workday:

Kids putting themselves in dangerous situations, like aggressing against each other is probably the most stressful and then second to that would be aggressing against me, like being oppositional, so defiance and reckless behavior. There will be a handful of kids who come looking for a fight ... literally and figuratively from the time they step foot on the campus.

In her letter to a first-year teacher, Anne explained the intersecting relationship stress with students:

I can have a child, a bright and sunny child, broken to pieces by some incident at home that I can't help, see, or fix from here, happen in an evening. A pandemic can change the face of education in a matter of weeks. 
Although teaching is an inherently stressing career, it is possible to decrease stress. Teachers experience somewhat elevated or high levels of stress and burnout in their personal, their work, and their student-related life (Harmsen et al., 2018). Eric explained

\begin{abstract}
My level of stress has significantly reduced since my first five years. Experience and classroom management make a monumental difference. Flexibility and building relationships also make a huge difference. So, I said a 3 because I'm relatively low stress at work. When there is a fight, I'm at a 10. When my class just won't stop goofing off, I'm at a 7. But generally, it's low because I've developed good management skills, build relationships, and try to be flexible and understanding.
\end{abstract}

\title{
Loved Ones
}

Burnout is job-related with late stages of burnout pervasively affecting non-work areas as well (Szigeti et al., 2016). The Holmes and Rahe Social Readjustment Rating Scale (Holmes \& Rahe, 1967) includes life events with a different weight assigned to it that determines the stress factor (Holmes \& Rahe, 1967). The higher the stress factor, the more likely the patient would become ill from stress related life events. During the focus group interview, Heather stated

I would say that my home life does not affect my stress level at work as much as my work stress affects my home life.

Many teachers nodded in agreement. Kinsley also agreed to the intersection of work and home stress, and stated:

I cannot forget about that parent email when I get home or I'll try to figure out ways that I'll respond, like Eric said, ruminating about things throughout the day when you get home. It's the complete opposite when I get to school, I don't think about anything else other than school when I'm there.

Teachers openly discussed the new stressors of teaching and living with COVID-19, Marissa explained:

You know, I've got three kids, not just that, but all three of them, well two out of the three of them are in a high-risk category. ... So, balancing their care as well as not wanting to let that guilt of being a teacher in this time frame, wanting what's best for my students but not wanting to get my family sick. I can't turn that off. It's been a real struggle just the last several months.

Anne described her stress during the one-on-one interview due to a job loss connected with COVID-19

My significant other didn't have a job for about a year, so that was adding a lot of stress and financial troubles. Our house, our mortgage has been in forbearance for a while. 
Teachers who experience chronic stress experience this because their brain gets locked into a recurring pattern, which may include ruinations, pessimistic thinking, and depression (Taylor, 2018).

\section{Theme 2: Intersecting Environmental Stress}

The second theme that emerged was intersecting environmental stress. School climate can foster resilience or become a risk factor and has been linked to teacher burnout, work commitment, and school connectedness (Embse et al., 2016). Gavin highlighted the need to balance both environments.

Some days you go home and feel like you have nothing left, teaching can sometimes drain the life out of you. It is an environment like no other, often full of chaos. That is why I make sure that my home environment is very organized, quiet, and calm. That keeps me balanced.

See Table 3 for subthemes and respective codes found in the data.

Table 3

Theme 2: Intersecting Environmental Stress

\begin{tabular}{ll}
\hline Subtheme & Code (frequency) \\
\hline $\begin{array}{l}\text { Navigating the School } \\
\text { Environment }\end{array}$ & $\begin{array}{l}\text { Classroom management (12) } \\
\text { Rules and regulations (10) } \\
\text { Resources (8) }\end{array}$ \\
\hline $\begin{array}{l}\text { Navigating the Home } \\
\text { Environment }\end{array}$ & $\begin{array}{l}\text { Time for loved ones (11) } \\
\text { Time for yourself (9) } \\
\text { Home organization (8) }\end{array}$ \\
\hline
\end{tabular}

\section{Navigating the School Environment}

Teacher well-being is influenced by school climate factors (Yu et al., 2016). The absence of support, challenging working conditions, and an overwhelming workload contribute to high teacher attrition (Goldring et al., 2014). In the focus group interview, Heather mentioned her environmental stressors at work, and many other teachers concurred and related to the statement:

There's just a lot I didn't know in the beginning and it was definitely stressful trying to figure it all out. First, they gave us a huge play book about how everything worked, but unless you're going to sit there and read through all the hundreds of pages on how to navigate the school and how to navigate your resources, that was definitely something that was hard for me to get used to.

It is not only the beginning teachers that are leaving the teaching profession at alarming rates; it's the experienced teachers as well (Glazer, 2018). Pam reflected on navigating her work environment during the one-on-one interview:

The worst and most stressful parts of my day are probably morning and afternoon duty, it's the worst way to start and end my day. I wish 
teachers could focus on the lessons for that day and not worry about the hallway areas and the before and after school areas. Picking up trash after kids, things like that. We have enough to deal with and worry about as it is.

\section{Navigating the Home Environment}

Teachers are found to have poorer perceived mental and physical health than a general healthy population (Uzman \& Telef, 2015). Psychosocial stress contributes to poor health in part by adversely affecting maintenance of healthy behaviors (Burg et al., 2017). Intersecting environmental stressors at home were discussed during the group interview and Heather stated:

I totally agree with you Julia, because when I get home, all I want to do when I get home is sleep. My boyfriend, he'll be like 'What do you want for dinner?' I don't care. He and I don't get to do anything really after school because there's nothing I want to do.

Kinsley discussed working a second job (DeNisco, 2018) at a supermarket because she recently bought a house and then her husband lost his job:

Now that I won't have my extra $6^{\text {th }}$ period class, that's another thing, is making sure that I can compensate for not having the extra money to put into my saving account. I work as a produce clerk, so that kind of helps me take my mind off of school and make up for that extra money that I won't be getting for my $6^{\text {th }}$ period. So, it's nice to go there and do something different because lettuce doesn't talk back when you put it someplace.

\section{Theme Three: Coping with Relationships}

Teacher educators have a responsibility to provide information about teacher stress and coping strategies in teacher preparation courses in order to give teachers the skills to deal with stress and burnout in an effective manner (Cancio \& Johns, 2013; Cancio et al., 2018). Coping with professional relationships and coping with personal relationships were the reoccurring subthemes found in the data within coping with relationships (see Table 4).

\section{Table 4}

Theme 3: Coping with Relationships

\begin{tabular}{ll}
\hline Subtheme & Code \\
\hline Coping with Professional & Students (22) \\
Relationships & Colleagues (14) \\
& Administrators (11) \\
& Mentors (6) \\
& \\
Coping with Personal & Children (12) \\
Relationships & Oneself (10) \\
& Spouse (9) \\
\hline
\end{tabular}




\title{
Coping with Professional Relationships
}

School administrators control many variables that influence teacher stress including autonomy over classrooms, workload, motivation, and support (Harmsen et al., 2018). Administrations can benefit from being more sensitive to the aspects of classroom conditions in their buildings that teachers perceive as most demanding and to those individual teachers who perceive an imbalance between resources and demands (McCarthy et al., 2015). During her one-on-one interview, Pam discussed how professional relationships with administration played an integral part in her everyday stress levels:

\begin{abstract}
I've moved schools because of poor leadership and overly stressful administrators. Having an understanding and supportive administration can make or break your stress levels at work. For me, that is my number one stressor. Knowing that my boss, or the school principal, has my back and trusts me professionally, means everything in the field of teaching.
\end{abstract}

When administrators create a supportive, organized, and collaborative environment, it supports teacher well-being (Skaalvik, 2011). Mentors of beginning teachers should assist in helping novice teachers to maintain perspective, come to work prepared with a mindset of high frustration tolerance, be aware of the negative impact of demandingness, and to not take things too personally (Bernard, 2016). In his letter writing sample, Eric explains coping with professional relationships:

You are a colleague, maybe a co-teacher, a shining example of how to be. You are all that and more every period of every day, and if you're not exhausted by the end of the day then you have superpowers that defy explanation.

\section{Coping with Personal Relationships}

Some teachers may combat stress by reaching out to friends, family, colleagues, administrators, and their health care providers (Ferguson et al., 2017). In the analysis of coping strategies for teachers, it was found that listening to music, feeling supported by family and friends, and dancing were strategies that predicted lower stress (Cancio et al., 2018). Val discusses coping with her personal relationships at home:

When it comes to my son and I, we just kind of separate ourselves. I'll give him something to go and do, and I'll go do something different. And just having that quiet time, and he likes to be with me which is fabulous.

Eric mentioned the importance of a supportive spouse in navigating personal relationships. He also discussed pressures brough on by having a family.

I have young children and just having young children is a source of stress in and of itself that is lots of stress. The daily grind of bills and meeting expectations here at home and taking care of a family, I think that's a source of stress. 


\section{Theme Four: Coping with the Environment}

The fourth theme that emerged was coping with the environment. In active coping strategies, teachers attempted to change the source of stress, or themselves, by engaging in leisurely activities such as dancing, yoga, exercise, and emotional support from family and friends (Burg et al., 2017). Three subthemes emerged (see Table 5).

\section{Table 5}

Theme 4: Coping with the Environment

\begin{tabular}{|c|c|}
\hline Subtheme & Code \\
\hline Tactile Objects & $\begin{array}{l}\text { Drinks (8) } \\
\text { Toys (7) } \\
\text { Home projects (6) }\end{array}$ \\
\hline Medication & $\begin{array}{l}\text { Prescription (8) } \\
\text { Over the counter (4) }\end{array}$ \\
\hline Physical Activity & $\begin{array}{l}\text { Working out (11) } \\
\text { Cleaning (8) } \\
\text { Walking dogs (4) }\end{array}$ \\
\hline
\end{tabular}

\section{Tactile Objects}

Chronic and acute stress, and the demanding features of daily life, can serve as a blockade to good health practices and lead to an unhealthy lifestyle (Burg et al., 2017). While stress can be very personal and vary from person to person, teachers need to make self-care a priority, and teachers need to feel safe in talking about stress without fear of stigma (Ferguson et al., 2017). During the focus group interview, Anne discussed using tactile objects to cope with stress:

When I'm at school, I'm definitely someone that is more tactile, I have little kinetic animals, full of kinetic sand, things that I kind of squish. They're comfort things, I have a blanket I keep at my desk that I wrap around me when I'm sitting at my desk. They're things that make me feel safe in a way, because my desk is my space, especially for me, like my kids know this very well.

Gabby added how she uses tactile objects to also cope with stress:

I'm kind of obsessive about touching up paint, if anybody runs into the wall wrong. I also love coloring. It's very satisfying. I also love taking care of my dog who is in the custody battle.

Kinsley explained one of her coping mechanisms during her one-on-one interview:

I try to keep a refrigerator full of things I enjoy drinking like sparkling water or tea. Something that is a little bit homey so I can have some of that too while I'm at school. 


\title{
Medication
}

In maladaptive coping strategies, teachers avoid or deny the source of stress (Cancio et al., 2018). Maladaptive coping strategies, like alcohol, drugs, and prescription medicine, were found to be predictors of stress (Mclean et al., 2017). In the one-on-one interview, Anne discussed her prescribed medications used to combat stress:

\begin{abstract}
I started taking Lexapro. I was on a 10mg dose, but I had to back it off because I was almost like tuned out, I was having a really hard time crying or feeling anything. It did help me as far as school goes in helping me be able to process and thinking things through. I used to be a very angry person, a reaction person. I also have chronic migraines and that would kind of manifest my stress that way too. I take medications for that.
\end{abstract}

The use of medication was openly discussed during the focus group interview. Marissa shared with the group

I am currently taking medication for my anxiety, because it's so bad. I knew I always had mild anxiety which usually could be dealt with by coping mechanisms, like listening to music, or taking my kids to the park, but now, it's kind of like all consuming, I can't focus on anything productive. Whether that's school or home or raising my kids the way I want them to be raised. So, anxiety medications.

Julia also shared her experiences with prescription medications for anxiety:

I went through that this summer. I've been taking medications for about a year, since that big school incident. You all know what I'm speaking of in the hallway and I became, what did they tell me, like when you used to something and it's not effective anymore, desensitized. So, they switched me recently and upped it even more recently. All right, this is good, this is good. I'm feeling excited and I'm feeling like I can be productive about stuff. There will always be stressors; it's just a matter of feeling like I can get passed it.

Heather added to the focus group interview about coping mechanisms:

I want to let you know that you're not alone there. My first year was last year. It was a lot for me, I had to see a counselor at one point, and she did teach me a lot of coping mechanisms. A lot of I think, what I suffered with was just accepting that things are new for me, and just excepting that and it's going to take a while for me to get used to it. It's important for people to know that they can ask others for help. And, that's something I wrote about in my letter too. It's ok if you feel like you can't handle it all, then don't do it all, you're not alone, I'm in the same boat.

Plausibly, teachers are no longer able to balance the long hours and heavy teaching workload requirements with leisurely activities such as exercise, meditation, or dance (Frank et 
al., 2013; Guidetti et al., 2019). Instead, they may be turning to quicker and easier methods of coping, such as prescribed medications (Cancio et. al., 2018).

\section{Physical Activity}

For some, regular physical activity can alleviate the physiological impact of chronic and acute stress while improving aspects of stress resilience (Burg et al., 2017). During the one-onone interview, Val discusses coping with her home environment:

I work out in the yard a lot. The more stress I get, I tend to clean more. I'm kind of one of those if I need to distress, I'll go clean my house, so that's a big one for me, working out in the yard and cleaning are probably my two biggest stress relievers.

Gabby also described strategies she uses to cope with her stressors:

I live in a brand-new house. I love taking care of it. I get this long extension pole, and if I dip it into this stuff called Cutters Gutters, whatever, it takes this stuff right off and it's all clean. I'm kind of obsessive about touching up paint if anybody runs into the wall wrong. I'm nesting.

\section{Discussion}

The purpose of this case study was to examine the intersection of personal and professional stress in the lives of public middle school teachers. Four themes emerged through the data analysis: (a) intersecting relationship stress, (b) intersecting environmental stress, (c) coping with relationships, and (d) coping with the environment. These results filled the gap in the existing literature surrounding personal and professional stress in the lives of public middle school teachers. Participants discussed professional relationships and how some coworkers were difficult to work with, adding to the workday stress. Participants also mentioned relationship stress at home, with roommates, kids, and spouses. At work, teachers described stress from monitoring the hallways, stress in the afternoon areas, and the new teacher stress of navigating a new school building. At home, participants described the stress of raising their children in a healthy environment, the unknowns of the COVID-19 virus, keeping their loved ones safe, and financial stress.

The findings also relate to empirical and theoretical literature discussed previously. Theoretical literature was guided by Maslach and Leiter's burnout theory (1997). Empirical research was presented in the literature review to provide information on the intersection of professional and personal stress with public middle school teachers along with their established coping strategies. The findings from this present study mentioned extended previous research and extended all six categories of burnout. The six categories provide individuals and organizations with the framework, along with the necessary tools, to move from burnout towards engagement (Maslach \& Leiter, 2005). Teachers in this study described stress from workload, control, reward, fairness, and values. The categories of reward and workload are expressed in Val's statement, "teaching is a rough profession because you get paid very little for the amount of work you do." This aligns with the research that low stress and overall wellness are relatively rare with teachers (Herman et al., 2018).

Empirical literature suggests that workload, perception of work environment, teachers' perceptions of senior management, and attitude towards change are specific perceived occupational difficulties of teachers and potentially cause higher than normal attrition rates 
(Ford et al., 2019; Simone et al., 2016). This current study corroborated these same points concerning teacher stress. The teachers interviewed described the stressors of frequently changing teacher evaluation methods along with the recurring adjustments of administration. Gavin mentioned the following: "There always seems like a new trend or best practice pops up every school year that administrators buy into and want to enforce and then it quickly fades away to the next new popular initiative that only serves to create extra work for teachers." During the one-on-one interview Eric described lack of student discipline as one of his major stressors, "hallway behavior is a regular source of stress, in school, especially around a classroom." It was concluded that stress causes and lack of resources result in emotional exhaustion, which significantly relate to intention to leave the profession (Ford et al., 2019; McCarthy et al., 2015).

Findings diverged from the previous research (Aguilar, 2018; Pas et al., 2012), because in this study, teachers turned the seemingly negative aspects of teacher stress into positives. Turning negative stress into positive stress was a strategy some teachers used to overcome stress and burnout. These findings contributed to the research, by shedding further light on teacher burnout and attrition, along with strategies used by public middle school teachers to fight against burnout. All teachers recognized the very challenging, taxing, and difficult job of teaching. Teachers face burnout because of time pressures, poor work environment, administrative problems, students' behavior issues, and changes in the educational system (Pas et al., 2012). The teachers in the current study, however, were able to come up with strategies and different ways of thinking about stress, in order to combat stressors leading to burnout (Mulyani et al., 2021). Previously, teachers were shown to seldom speak to their health care providers about stress issues and they were not comfortable with talking to their principals about stress (Ferguson et al., 2017). In this case study multiple participants were able to openly discuss medication use and these open discussions could lead to improvements in self-care (Frank et al., 2016; Herman et al., 2018;). Further, studies have found that burnout in teachers is often caused by perception of work environment, workload, teachers' perceptions of senior management, and attitude towards change (Simone et al., 2016). The present study found burnout to be related to these things, in addition to coworkers, students, and loved ones. In this study, the negative stressors with coworkers were described as lack of communication, lack of understanding, and lack of follow through.

\section{Practical Implications}

The existing literature has practical implications for public middle school teachers:

- increased happiness

- alleviate teacher shortages

- $\quad$ positive impact on students

- improved work-life balance

Allowing teachers to focus on their cognitive, physical, and emotional wellbeing could make a big difference in the happiness and job satisfaction of teachers. It could help in the job retention and shortage problem with classroom teachers, especially public middle school teachers. The core aspect of burnout is the emotional exhaustion, the chronic feeling of tiredness and fatigue, which make teachers lose their enthusiasm (Szigeti et al., 2016). Teachers' mental health has a widespread impact not only on teaching effectiveness; it also has a big impact on students' personal development, emotional development, and academic achievement (Oberle et al., 2021; Szigeti et al., 2016). If our best and most passionate teachers leave the profession because of burnout and stress build up, it is the students that will miss out. The teachers in this study mentioned the use of exercise, journaling, mediation, cleaning, and napping as ways to 
cope with stress. It is critical for teachers to deal with the work stressors of their profession using coping strategies, work-life balance, meaningful collaboration, support from coworkers, and support from teaching staff (Harmsen et al., 2018).

\section{Limitations}

This study comprised a set of boundaries that helped preserve the focus of examining the intersection of personal and professional stress in the lives of public middle school teachers, along with coping strategies to manage that stress. Purposeful sampling was employed to maximize variation in participant diversity, but this choice eliminated possible participants in the study who may have given an alternate perspective. A gender bias (eight female/two male participants) may have been present the perspectives and experiences of mostly females were obtained. Two participants withdrew from the study after initially giving consent. The study also selected participants from a single middle school where using multiple locations may have allowed for cross case analysis (Stake, 2005). Another limitation in this study was the use of online interviews through video conferencing software. Due to the COVID-19 pandemic, meeting online was the safest option. In-person interviews would have possibly provided higher-quality data. Although teachers answered the interview questions in real time, and provided in-depth responses, in person interviews may have provided further insight into the questions asked. In person interviews can better resemble guided conservations and can be more personalized.

\section{Recommendations}

There is a necessity to pay attention to prospective teachers' mental health, promote formal sources of help, and overcome seeking help obstacles (Uzman \& Telef, 2015). More studies need to be performed to deepen our understanding of teachers' current job dissatisfaction and burnout. Despite the importance of teachers' emotional experiences, most teachers have never experienced any professional development sessions that talk about how to handle emotions in the classroom or how to recover from emotional trauma (Hong, 2012). Future studies with more time and resources could take advantage of a more in-depth multicase study design. A multi-case study design could be used to study, compare, and contrast other public middle schools as it relates to stress and burnout. Policies need to be developed aimed at encouraging job satisfaction among teachers, and positively interfering with their work condition, in order to promote their health and well-being (Benevene at. el., 2018).

\section{Funding Details}

No grants or financial incentives were involved in this study.

\section{Disclosure Statement}

There was no personal or professional relationship between the researchers and participants of this study.

\section{References}

Aguilar, E. (2018). Emotional resilience: The missing ingredient. Educational Leadership, 5, 1-8. https://www.ascd.org/el/articles/emotional-resilience-the-missing-ingredient 
Benevene, P., Ittan, M., \& Cortini, M. (2018). Self-esteem and happiness as predictors of school teachers' health: The mediating role of job satisfaction. Frontiers in Psychology, 9, 15. https://doi.org/10.3389/fpsyg.2018.00933

Bernard, M. (2016). Teacher beliefs and stress. Journal of Rational Emotive and CognitiveBehavior Therapy, 34, 1-16. https://doi.org/10.1007/s10942-016-0238-y

Bogaert, I., Martelaer, K., Deforche, B., Clarys, P., \& Zinzen, E. (2014). Associations between different types of physical activity and teachers' perceived mental, physical, and workrelated health. BMC Public Health, 14(53), 518-534. http://www.biomedcentral.com/1471-2458/14/534

Brewers, P., Myers, S., \& Zhang, M. (2015). Islands unto themselves: How merit pay schemes may undermine positive teacher collaboration. Critical Questions in Education, 6, 4554.

Burg, M., Schwartz, J., Kronish, I., Diaz, K., Alcantara, C., Davidson, K. (2017). Does stress result in you exercising less? Or does exercising result in you being less stressed? Or is it both? The Society of Behavioral Medicine, 51, 799-809. https://doi.org/10.1007/s12160-017-9902-4

Cancio, E., \& Johns, B. (2013). Defining administrative support and its relationship to the attrition of teachers of students with emotional and behavioral disorders. Education \& Treatment of Children, 36(4), 71-98.

Cancio, E., Larsen, R., Mathus, S., Estes, M., Johns, B., \& Chang, M. (2018). Special education teacher stress: Coping strategies. Education and Treatment of Children, 41, 457-482. https://muse.jhu.edu/article/705292

Carver-Thomas, D., Darling-Hammond, L. (2017). Teacher turnover: Why it matters and what we can do about it. Learning Policy Institute. ERIC Number: ED606805.

Creswell, J. W. (2013). Qualitative inquiry \& research design: Choosing among five approaches (3rd ed.). Sage Publications.

Cross, B. \& Thomas, C. (2017). Mitigating first year burnout: How reimagined partnerships could support urban middle level teachers. Middle Grades Review, 3(1), 23-33.

Day, C., \& Gu, Q. (2010). The new lives of teachers. Routledge.

DeNisco, A. (2018). District policies target teachers' second jobs. District Administration, 54(11), 19.

Durour, R., \& Marzano, R. (2013). Leaders of learning: How district, school, and classroom leaders improve student achievement. Solution Tree.

Embse, N., Pendergast, L., Segool, N., Saeki, E., \& Ryan, S. (2016). The influence of test-based accountability policies on school climate and teacher stress across four states. Teaching and Teacher Education, 59, 492-502. https://doi.org/10.1016/j.tate.2016.07.013

Farmer, D. (2020). Teacher attrition: The impacts of stress. Delta Kappa Gamma Bulletin, 87(1), 41-50.

Ferguson, K., Mang, C., \& Frost, L. (2017). Teacher stress and social support usage. Brock Education Journal, 26(2), 62-86. https://doi.org/10.26522/brocked.v26i2.606

Ford, T. G., Olsen, J., Khojasteh, J., Ware, J., \& Urick, A. (2019). The effects of leader support for teacher psychological needs on teacher burnout, commitment, and intent to leave. Journal of Educational Administration, 57(6), 615-634. https://www.emerald.com/insight/content/doi/10.1108/JEA-09-2018-0185/full/html

Frank J., Jennings P., \& Greenberg M. (2016). Validation of the mindfulness in teaching scale. Mindfulness, 7(1), 155-163. https://link.springer.com/article/10.1007/s12671-0150461-0

Frank J., Reibel D., Broderick P., Cantrell T., Metz S. (2013). The effectiveness of mindfulnessbased stress reduction on educator stress and well-being: results from a pilot study. Mindfulness, 6(2), 208-216. https://link.springer.com/article/10.1007/s12671-0130246-2 
Fullan, M. (2010) The awesome power of the principal. Principal, 89(4), 10-12.

Fuming, X., \& Jiliang, S. (2007). Research on job satisfaction of elementary and high school teachers and strategies to increase job satisfaction. Chinese Education and Society, 40(5), 86-96. https://doi.org/10.2753/CED1061-1932400509

Gentilucci, J. L., \& Muto, C. C. (2007). Principals' influence on academic achievement: The student perspective. NASSP Bulletin, 91(3), 219-236. https://doi.org/10.1177/0192636507303738.

Glazer, J. (2018). Learning from those who no longer teach: Viewing teacher attrition through a resistance lens. Teaching and Teacher Education, 74, 62-71. https://doi.org/10.1016/j.tate.2018.04.011

Goldring, R., Taie, S., \& Riddles, M. (2014). Teacher attrition and mobility: Results from the 2012-13 teacher follow-up survey (NCES 2014-077). U.S. Department of Education. Washington, DC: National Center for Education Statistics.

Gray, C., Wilcox, G., \& Nordstokke, D. (2017). Teacher mental health, school climate, inclusive education, and student learning: A review. Candadian Psychology, 58, 203210. http://dx.doi.org/10.1037/cap0000117

Guidetti, G., Viotti, S., Badagliacca, R., Colombo, L., Converso, D. (2019). Can mindfulness mitigate the energy depleting process and increase job resources to prevent burnout? A study on the mindfulness trait in the school context. Mindfulness, 3, 1-17. https://doi.org/10.1371/journal.pone.0214935

Harmsen, R., Helms, M., Maulana, R., \& Veen, K. (2018). The relationship between beginning teachers' stress causes, stress responses, teaching behavior, and attrition. Teachers and Teaching, 24, 626-643. https://doi.org/10.1080/13540602.2018.1465404

Harris, A., Jennings, P., Katz, D., Abenavoli, R, \& Greenberg, M. (2015). Promoting stress management and well-being in educators: Outcomes of the CALM intervention. Mindfulness, 7, 1-12. https://link.springer.com/article/10.1007/s12671-015-0451-2

Hartwick, J. (2013). Spiritual practices as a means of coping with and ameliorating stress to reduce teacher attrition. Journal of Research on Christian Education, 22, 165188.https://doi.org/10.1080/10656219.2013.808979

Herman, K., Hickmon-Rosa, J., \& Reinke, W. (2018). Empirically derived profiles of teacher stress, burnout, self-efficacy, and coping and associated student outcomes. Journal of Positive Behavior Interventions, 20(2), 90-100. https://doi.org/10.1177/1098300717732066

Holmes, T., \& Rahe, R. (1967). The social readjustment rating scale. Journal of Psychosomatic Research, 11(2), 213-218.

Hong, J. (2012). Why do some beginning teachers leave the school, and others stay? Understanding teacher resilience through psychological lenses. Teachers and Teaching, 18(4), 417-440. https://doi.org/10.1080/13540602.2012.696044

Huberman, A.M., Grounauer, M. M., \& Marti, J. (1993). The lives of teachers. Cassel.

Iancu, A., Rusu, A., Maroiu, C., Maricutoiu, L. (2017). The effectiveness of interventions aimed at reducing teacher burnout: A meta-analysis. Educational Psychology Review. 30, 373396. https://doi.org/10.1007/s10648-017-9420-8

Ingersoll, R., Merrill, L., \& Stuckey, D. (2014). Seven trends: The transformation of the teaching force. CPRE Report.\# RR-80. Consortium for Policy Research in Education. https://doi.org/10.12698/cpre.2014.rr80

Katz, D., Harris, A., Abenzvoli, R., Greenberg, M., \& Jennings, P. (2017). Educators' emotion regulation strategies and their physiological indicators of chronic stress over 1 year. Human Development and Family Studies, 34, 278-285. https://doi.org/10.1002/smi.2782

Leiter, M.P. \& Maslach, C. (2000). Preventing burnout and building engagement: A complete program for organizational renewal. Jossey-Bass. 
Leiter, M.P. \& Maslach, C. (2005). Banishing burnout: Six strategies for improving your relationship with work. Jossey-Bass.

Maslach, C. (2003). Job burnout: New directions in research and intervention. Journal of Psychological Science, 12(5), 189-195.

Maslach, C. \& Leiter, M.P. (1997). The truth about burnout: How organizations cause personal stress and what to do about it. Jossey-Bass.

McCarthy, C. J., Lambert, R. G., Lineback, S., Fitchett, P., \& Baddouh, P. G. (2015). Assessing teacher appraisals and stress in the classroom: Review of the classroom appraisal of resources and demands. Educational Psychology Review, 28, 577-603. https://doi.org/10.1007/s10648-015-9322-6

McLean, L., Abry, T., Taylor, M, \& Granger, K. (2017). Teachers' mental health and perceptions of school climate across the transition from training to teaching. Teaching and Teacher Education, 65, 230-240. https://doi.org/10.1016/j.tate.2017.03.018

Mulyani, S., Salameh, A. A., Komariah, A., Timoshin, A., Hashim, N. A., Fauziah, R. S., Mulyaningsih, M., Ahmad, I., \& Ul din, S. M. (2021). Emotional regulation as a remedy for teacher burnout in special schools: Evaluating school climate, teacher's work-life balance and children behavior. Frontiers in Psychology, 12, 1-10. https://doi.org/10.1002/pits.22432

Newberry, M., \& Allsop, Y. (2017). Teacher attrition in the USA: The relational elements in a Utah case study. Teaching Theory and Practice, 23(8), 863-880. https://doi.org/10.1080/13540602.2017.1358705

Oberle, E., Gist, A., Cooray, M. S., \& Pinto, J. B. (2021). Do students notice stress in teachers? Associations between classroom teacher burnout and students' perceptions of teacher social-emotional competence. Psychology in Schools, 57, 1741-1756. https://doi.org/10.1002/pits.22432

Oyen, K. \& Schweinle, A. (2021). Addressing teacher shortages in rural America: What factors encourage teachers to consider teaching in rural settings? The Rural Educator, 41(3), 12-25. https://doi.org/10.35608/ruraled.v41i3.923

Pas, E., Bradshaw, T., \& Hershfeldt, P. (2012). Teachers and school level predictors of teacher efficacy and burnout: Identifying potential areas for support. Journal of School Psychology, 50, 129-145. https://doi.org/10.1016/j.jsp.2011.07.003

Patton, M. (2015). Qualitative Research \& Evaluation Methods ( $4^{\text {th }}$ ed.). SAGE Publications, Inc.

Pignata, S. \& Winefiled, A. (2013). Stress-reduction interventions in an Australian university: A case study. Stress and Health, 31(1), 213-246. https://doi.org/10.1002/smi.2517

Rupesh, R., \& Bibhas, C., (2017). Exploring predictors of burnout and work engagement among teachers: A review on higher educational institutions of India. Journal of the Indian Academy of Applied Psychology, 48(1), 145-156.

Scully, J. \& Tosi, H. (2000). Life event checklists: Revisiting the social readjustment rating scale after 30 years. Educational and Psychological Measurement, 60(6), 864-876.

Shin, H., Noh H., Jang, Y., Park Y. \& Lee, S. (2014). A longitudinal examination of the relationship between teacher burnout and depression. Journal of Employment Counseling, 50(3), 124-137. https://doi.org/10.1002/j.2161-1920.2013.00031.x

Simone, S., Cicotto, G., \& Lampis, J. (2016). Occupational stress, job satisfaction and physical health in teachers. Science Direct, 66, 65-77. https://doi.org/10.1016/j.erap.2016.03.002

Skaalvik, E. (2011). Teacher job satisfaction and motivation to leave the profession: Relations with school context, feeling of belonging, and emotional exhaustion. Teacher and Teacher Education, 27(6), 1029-1038. https://doi.org/10.1016/j.tate.2011.04.001

Sorenson, L. \& Ladd, H. (2020). The hidden costs of teacher turnover. Sage Journals, 6(1), 124. https://doi.org/10.1177/2332858420905812

Stake, R. E. (2005). Multiple case study analysis. The Guilford Press. 
Stauffer, S. D., \& Mason, C. M. (2013). Addressing elementary school teachers' professional stressors. Educational Administration $\quad$ Quarterly, 49, 809837. https://doi.org/10.1177/0013161X13482578

Szigeti, R., Balaza, N., Bikfalvi, R., \& Urban, R. (2016). Burnout and depressive symptoms in teachers: Factor structure and construct validity of the Maslach Burnout inventory. Stress and Health, 33, 530-539. https://doi.org/10.1002/smi.2737

Taylor, M. (2018). CALMERSS to enhance teacher well-being: A pilot study. International Journal of Disability, Development and Education. 65(3), 243-261. https://doi.org/10.1080/1034912X.2017.1394985

Tuckey, M., Dollard, M., \& Bakker, A. (2012). Empowering leaders optimize working conditions for engagement: A multilevel study. Journal of Occupational Health Psychology, 17, 15-27. https://doi.org/10.1037/a0025942

Uzman, E., \& Telef, B. (2015). Prospective teachers' mental health and their help-seeking behaviors. The Journal of Psychiatry and Neurological Sciences, 28, 242-254. https://doi.org/10.5350/DAJPN2015280307

Woloshyn, V. \& Savage, N. (2018). Increasing teacher candidates' mental health literacy and stress coping skills through and elective mental health and wellness course. International Journal of Inclusive Education, 28(9), 921-935. https://doi.org/10.1080/13603116.2018.1497097

Xin Z., Hongbiao Y., \& Xiaofang, W. (2021). Doing authentic research with artifacts to facilitate teacher learning across multiple communities. Teaching and Teacher Education, 105, 1-14. https://doi.org/10.1016/j.tate.2021.103394

Yin, R. (2018). Case study research: Design and methods (5th ed.). Sage Publishing.

Yu, G., Dong, Y., Want, Q., \& An, R. (2016). Reducing teacher stress: Improving humanized management of Chinese teachers. Journal of Chinese Human Resource Management, 7(2), 82-99. https://doi.org/10.1108/JCHRM-07-2016-0014

Zysberg, L., Orenhtein, C., \& Robinson, R. (2017). Emotional intelligence, personality, stress, and burnout among educators. International Journal of Stress Management, 24(1), 122136. https://doi.org/10.1037/str0000028

\section{Notes on Contributors}

Bridgette Wicke, EdD, is a middle school math teacher in the public schools of Florida with teaching experience at all levels of K-12 education. She has earned her National Board Teacher Certification in Middle Childhood Generalist and has earned professional teaching certifications in Mathematics, Elementary Education, Physical Education, Gifted Education, and Educational Leadership. Correspondence should be sent to drbwicke@gmail.com; ORCID - 0000-0002-5856-7494

Timothy R. Nelson, EdD, is a National Board-certified middle school math teacher in the public schools of South Carolina with teaching and administrative experience at all levels of K-12 education. In addition to his work there, he teaches graduate courses on research methodology, educational statistics, and professional publication for Liberty University. He has published research on technology use in middle level mathematics and job satisfaction. Correspondence should be sent to trnelson2@liberty.edu; ORCID ID - 0000-0002-6976-6149

Manuscript received August 11, 2021

Final revision received November 20, 2021

Accepted November 26, 2021 